\title{
Manajemen Jaringan Internet di Dinas Kesehatan Provinsi Bali Dengan Menggunakan Hierarchical Token Bucket
}

\author{
I Gede Abi Yodita Utama ${ }^{1}$, I Gusti Ngurah Agung Jaya Sasmita ${ }^{2}$, Lie Jasa ${ }^{3}$ \\ [Submission: 09-09-2020, Accepted: 04-12-2020]
}

\begin{abstract}
The digital age 4.0 brings changes in the use of the internet network. The needs of internet is no longer a secondary need but becoming a primary need. Utilization of the internet network at the Bali Government Department of Health Service is often not used wisely which is impacting the access and connectivity. In addition, it also disrupting services to the community. Internet network management is also not well managed here. Hierarchical Token Bucket (HTB) is a way of internet network management using packet scheduling such as bandwidth management to every client. HTB implementation is able to maximize unused bandwidth. As the result for that, it will improve service quality. Implementation of HTB with MikroTik at the Bali Government Department of Health results in an even distribution of bandwidth based on bucket size, priority, CIR and MIR values. The division also does not interfere with access and connectivity in each section / field.
\end{abstract}

Intisari- Era digital 4.0 membawa perubahan dalam pemanfaatan jaringan internet. Kebutuhan akan internet tidak lagi menjadi kebutuhan sekunder melainkan menjadi kebutuhan primer. Pemanfaatan jaringan internet di Dinas Kesehatan Provinsi Bali sering kali tidak digunakan secara bijak dimana berdampak pada akses dan konektivitas menjadi terhambat dan mengganggu pelayanan kepada masyarakat. Manajemen jaringan internet juga belum dikelola dengan baik. Hierarchical Token Bucket (HTB) merupakan cara manajemen jaringan internet melalui penjadwalan paket seperti pengaturan bandwith kepada masing-masing client. Penerapan HTB mampu memaksimalkan bandwidth yang tidak terpakai, sehingga dapat meningkatkan kualitas layanan menjadi lebih baik Implementasi HTB dengan MikroTik pada Dinas Kesehatan Provinsi Bali menghasilkan pembagian bandwith secara merata berdasarkan bucket size, priority, nilai CIR dan MIR. Pembagian tersebut juga tidak mengganggu akses dan konektivitas pada tiap-tiap bagian/bidang.

Kata Kunci-Hierarchical Token Bucket, Queueing, MikroTik, CIR, MIR

\section{PENDAHULUAN}

Perkembangan teknologi informasi berdampak pada berubahnya paradigma dalam mencari suatu informasi. Semula informasi hanya didapatkan melalui media cetak seperti koran, majalah, tabloid dan lain sebagainya, dengan berkembangnya jaringan internet informasi tersebut bisa diperoleh secara cepat melalui perangkat yang terhubung ke

\footnotetext{
1,2 Mahasiswa, Magister Teknik Elektro Universitas Udayana, Jl. P.B. Sudirman, Denpasar, Bali, Indonesia 80114 (tlp: 0361555225; fax: 0361-4321982; e-mail: kingkonggede89@gmail.com, gillcoding23@gmail.com)

${ }^{3}$ Dosen, Magister Teknik Elektro Universitas Udayana, Jl. P.B. Sudirman, Denpasar, Bali, Indonesia 80114 (tlp: 0361555225; fax: 0361-4321982; e-mail: liejasa@unud.ac.id)
}

I Gede Abı Yodıta Utama: Manajemen Jarıngan Internet dı... jaringan internet seperti gadget, pc, super komputer, robot dan lain sebagainya. Perkembangan teknologi informasi bukan saja hanya melibatkan interaksi dengan orang, namun interaksi orang dengan benda, dan juga benda dengan benda [1]. Perkembangan teknologi informasi mencakup beberapa sektor seperti pemerintahan, pendidikan, industri, swasta dan lain sebagainya [2].

Era digital 4.0 membawa perubahan dalam pemanfaatan jaringan internet. Kebutuhan akan internet tidak lagi menjadi kebutuhan sekunder melainkan dapat dikatakan sejajar dengan kebutuhan primer. Teknologi yang dirancang dan didesain pada era ini untuk memenuhi kebutuhan hidup seseorang baik secara pribadi ataupun sosial, serta dampaknya dapat menjadi revolusi perilaku seseorang dalam kehidupan di era digital ini [3]. Era ini telah membawa perubahan terhadap pemanfaatan internet di sektor pemerintahan.

Dinas Kesehatan Provinsi Bali instansi pemerintah yang membantu gubernur dalam urusan kesehatan selalu berusaha untuk meningkatkan pelayanan kesehatan kepada masyarakat. Dengan berkembangnya era digital 4.0 pelayanan kesehatan kepada masyarakat dituntut secara cepat, tepat, efektif dan efisien. Melalui pemanfaatan internet diharapkan dapat mendukung pelayanan kesehatan kepada masyarakat tersebut.

Pemanfaatan jaringan internet tersebut sering tidak digunakan secara bijak, banyak aplikasi atau situs yang diakses tidak sesuai dengan keperluan untuk memberikan pelayanan atau menyelesaikan pekerjaan. Hal ini berdampak pada akses dan konektivitas internet menjadi terhambat dan menggangu pelayanan yang diberikan kepada masyarakat. Selama ini, manajemen jaringan internet di dinas kesehatan provinsi bali belum dikelola dengan baik, internet yang diteruskan dari Pusat Data Dinas Komunikasi, Informatika dan Statistik Provinsi Bali hanya dilakukan pembagian ke masing-masing bidang melalui switch tanpa dilakukan manajemen jaringan internet yang baik.

Hierarchical Token Bucket (HTB) merupakan salah satu cara untuk melakukan manajemen jaringan internet melalui penjadwalan paket seperti pengaturan bandwith kepada masing-masing client. Bandwidth akan dibagi sesuai dengan aturan yang diterapkan dan client mendapatkan akses dan konektivitas internet secara adil sesuai dengan pembagian yang ditentukan [4]. Penerapan HTB pada penelitian sebelumnya mampu memaksimalkan bandwidth yang tidak terpakai, sehingga dapat meningkatkan kualitas layanan menjadi lebih baik [5]. Dalam mengimplentasikan penerapan HTB dalam manajemen jaringan internet di Dinas Kesehatan Provinsi Bali, maka digunakan MikroTik. MikroTik memiliki fasilitas penjadwalan yang dapat digunakan dalam menganalisis dan melakukan pengaturan alokasi bandwidth untuk setiap komputer pengguna [6]. Diharapkan dengan

$$
\text { p-ISSN:1693 - 2951; e-ISSN: 2503-2372 }
$$


penerapan HTB ini manajemen bandwith dikelola dengan baik dan sesuai aturan pembagian yang diterapkan sehingga dapat memaksimalkan pemanfaatan akses internet untuk dapat meningkatkan pelayanan kesehatan kepada masyarakat dan dapat bekerja secara efektif dan efisien.

\section{TINJAUAN PUSTAKA}

\section{A. Hierarchical Token Bucket}

Hierarchical Token Bucket (HTB) adalah antrian berbasis kelas yang mampu menhasilkan antrian dan membagikan paket dalam urutan dan waktu ditentukan oleh algoritma yang disembunyikan di dalamnya. Dalam HTB pembagian dilakukan berdasarkan klasifikasi. Dengan menggunakan filter memudahkan dalam melakukan klasifikasi sehingga dapat membedakan perlakuan dalam mengalokasikan paket berdasarkan jenis dan prioritas dari client.

HTB menggunakan bucket dan token untuk melakukan kontrol traffic dan membagi bandwidth. Sistem dalam HTB disusun oleh kelas root, kelas interior dan kelas daun. Traffic dikendalikan oleh token, distribusi dari kelas akar ke kelas daun melalui kelas interior. Melalui skema ini bandwith dialokasikan secara merata sesuai prioritas dan tidak menitikberatkan pada salah satu client [7].

Monitoring traffic adalah kunci dalam melakukan kontrol dari suatu traffic internet. Dengan melakukan pemantauan arus traffic pada jaringan, kita dapat membuang atau menunda pengiriman paket jaringan yang berada di luar batas. Fungsi pemantauan traffic ini dapat dilakukan melalui mekanisme Token-Bucket [8]. Gambar 1 menunjukaan mekanisme klasifikasi dan pengaturan paket jaringan pada HTB.

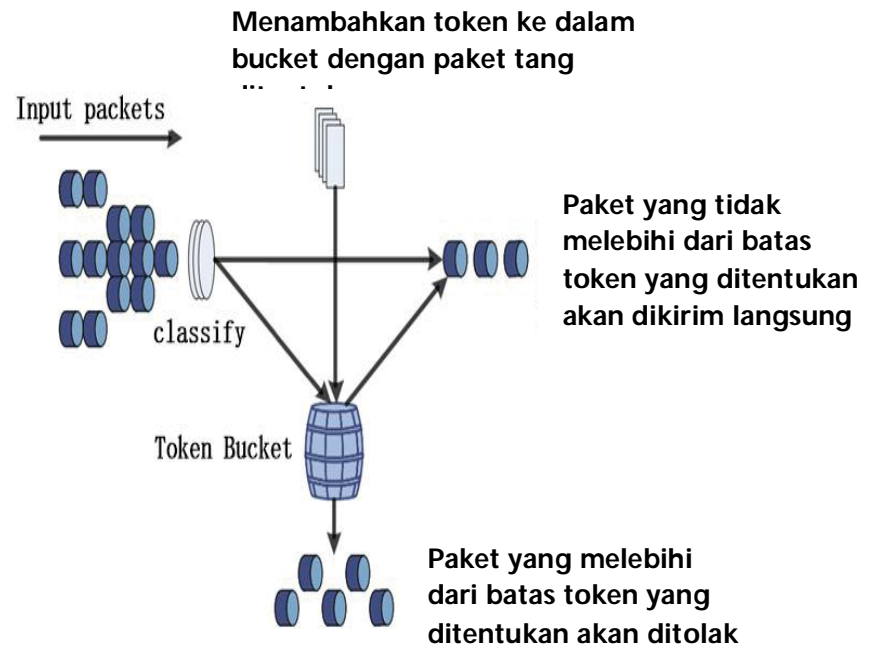

Gambar 1: Mekanisme Hierarchical Token Bucket

\section{B. MikroTik}

MikroTik menggunakan Linux sebagai sistem operasinya. MikroTik berperan dalam jaringan komputer sebagai router jaringan. MikroTik dirancang untuk memberikan kenyamanan dan kebebasan bagi penggunanya. Untuk melakukan pengaturan administrasi pada MikroTik dapat digunakan aplikasi Windows disebut dengan "WinBox" [9].

MikroTik hanya digunakan sebagai Gateway, apabila digunakan untuk jaringan yang kompleks harus disesuaikan dengan infrastruktur jaringan yang memadai. Spesifikasi dan fitur yang terdapat didalam MikroTik termasuk Firewall \& Nat, Hotspot, Routing, Pembatas Bandwidth, DNS server, Protokol Tunneling point to point, Hotspot, Server DHCP, dan banyak lagi. Dalam melakukan manajemen bandwidth pada MikroTik digunakan Queuing Tree. Queuing adalah penjadwalan suatu data dikirimkan melewati jaringan [10].

MikroTik adalah sistem operasi komputer yang dapat berperan dari komputer menjadi router. MikroTik dibagi menjadi dua jenis yaitu MikroTik RouterOS dan RouterBoard. MikroTik [11]. RouterBoard tidak memerlukan komputer untuk menjalankannya, dalam RouterBoard itu sudah dilengkapi dengan MikroTik RouterOS. Selain itu, dalam RouterBoard juga dilengkapi fitur yang khusus dibuat untuk jaringan IP dan jaringan nirkabel.

MikroTik RouterOS adalah sistem operasi yang dapat digunakan untuk melakukan memodifikasi dari suatu sistem komputer menjadi sebuah router jaringan, termasuk berbagai fitur yang dibuat untuk jaringan IP dan jaringan nirkabel. MikroTik RouterOS cocok untuk digunakan oleh ISP dan penyedia layanan hotspot. Dalam melakukan instalasi tidak memerlukan perangkat lunak tambahan atau alat tambahan lainnya. Operating System ini dibuat untuk melakukan manajemen administrasi jaringan internet seperti merancang dan membangun jaringan komputer untuk skala kecil ataupun sistem jaringan komputer ke yang kompleks.

\section{METODE PENELITIAN}

\section{A. Topologi Jaringan}

Dalam melakukan manajemen internet sebaiknya mengacu pada topologi jaringan yang disesuaikan dengan infrastruktur yang digunakan. Pada Dinas Kesehatan Provinsi Bali menggunakan 2 cara untuk terhubung ke jaringan internet Pusat Data Dinas Komunikasi, Informatika dan Statistik Provinsi Bali yaitu melalu Wireless Radio dan Fiber Optic. Perbedaan dari kedua komponen tersebut adalah pada kemampuan dalam mendistribusikan bandwith ke Dinas Kesehatan Provinsi Bali. Untuk Wireless Radio kemampuan mendistribusikan bandwith hanya berkisar antara 10-15 Mbps, sedangkan melalui Fiber Optic distribusi bandwith dapat diterima dengan kapasitas 100 Mbps. Kedua komponen infrastruktur tersebut akan masuk melalui core switch sebagai backbone dan dari core switch akan terhubung melalui RouterBoard MikroTik untuk dilakukan manjemen jaringan internet ke masing-masing Bidang/Bagian di Lingkungan Dinas Kesehatan Provinsi Bali. Area penelitian dilakukan pada RouterBoard MikroTik dengan menggunakan aplikasi MiktoTik versi windows yaitu "Winbox". Gambar 2 menunjukkan topologi jaringan internet di Dinas Kesehatan Provinsi Bali. 

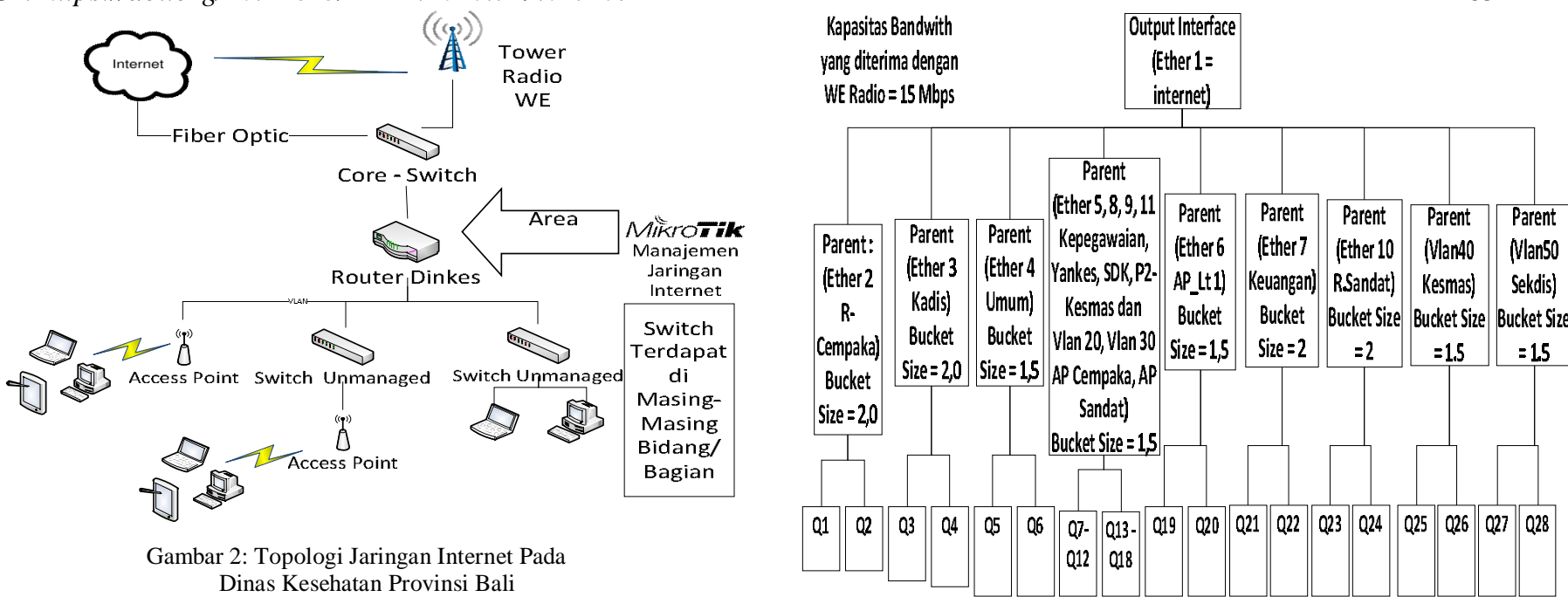

\section{B. Struktur Hierarchical Token Bucket}

Sebelum menginplementasikan HTB untuk manajemen jaringan internet di lingkungan Dinas Kesehatan Provinsi Bali terlebih dahulu proses pertama yang dilakukan adalah membuat mangle untuk menandai jenis paket yang akan dikirimkan kepada masing-masing bagian dan selanjutnya menyusun queue tree untuk membagi bandwith kepada masing-masing bagian, dalam queue tree inilah akan dilakukan implementasi Hierarchical Token Bucket. Diagram alur dari HTB dapat dilihat pada Gambar 3.

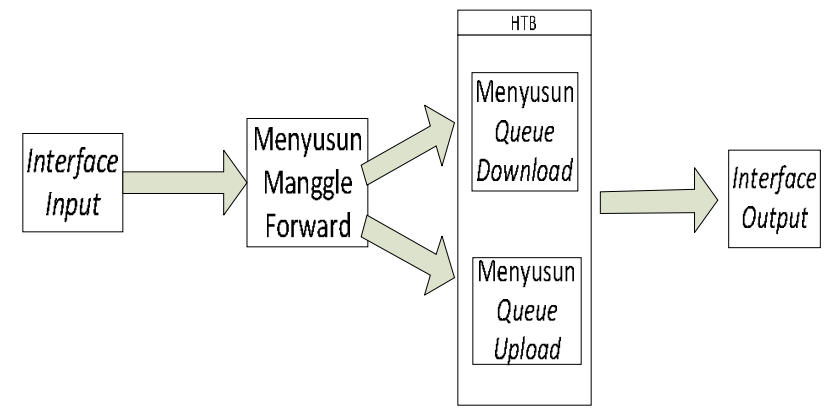

Gambar 3: Diagram Alur Hierarchical Token Bucket

Dalam menyusun queue yang akan digunakan untuk mengimplementasikan Hierarchical Token Bucket, pada Dinas Kesehatan Provinsi Bali dapat diterapkan 2 kondisi sesuai dengan permasalahan paket jaringan internet yang diterima dari pusat data Diskominfos Provinsi Bali. Dimana kondisi tersebut dapat digambarkan melalui struktur HTB. Kondisi pertama adalah ketika menerima paket melalui Radio WE yang dapat dilihat pada Gambar 4 dan kondisi kedua adalah ketikan menerima paket melalui fiber optic yang dapat dilihat pada Gambar 5.

\begin{tabular}{|c|c|c|}
\hline $\begin{array}{l}{ }^{*} \text { Q1 dan Q2 Cempaka Tele } \\
\text { Download }\end{array}$ & & \\
\hline Max-limit = 6 Mbps & & *027 dan 028 \\
\hline $\begin{array}{l}\text { Limit-At = } 5 \text { Mbps } \\
\text { Priority =1 }\end{array}$ & $\begin{array}{l}\text { Q19 dan Q20-Lantai } 1 \text { Diskes } \\
\text { Download }\end{array}$ & $\begin{array}{l}\text { Q21 dan Q28 } \\
\text { Sekretaris }\end{array}$ \\
\hline $\begin{array}{l}\text { Priority =1 } \\
\text { Upload }\end{array}$ & Max-limit = 4 Mbps & Download \\
\hline $\begin{array}{l}\text { Upload } \\
\text { Max-limit = } 6 \text { Mbps }\end{array}$ & Limit $-\mathbf{A t}=\mathbf{3} \mathrm{Mbps}$ & Max-limit $=3 \mathrm{Mbps}$ \\
\hline Limit $-\mathbf{A t}=5 \mathrm{Mbps}$ & Priority $=\mathbf{3}$ & Limit $-A t=2 \mathrm{Mbps}$ \\
\hline Priority = 1 & Upload & Priority = 2 \\
\hline & Max-limit $=4$ Mbps & Upload \\
\hline${ }^{*}$ Q3 dan Q4 - Kadis & Limit $-\mathbf{A t}=\mathbf{3} \mathrm{Mbps}$ & Max-limit = $\mathbf{3}$ Mbps \\
\hline Download & Priority $=\mathbf{3}$ & Limit $-\mathbf{A t}=\mathbf{2} \mathrm{Mbps}$ \\
\hline $\begin{array}{l}\text { Max-limit }=5 \mathrm{Mbps} \\
\text { Limit }-\mathrm{At}=4 \mathrm{Mbps}\end{array}$ & & Priority $=\mathbf{2}$ \\
\hline $\begin{array}{l}\text { Limit-At }=4 \text { Mbps } \\
\text { Priority }=2\end{array}$ & *Q21 dan Q22 Bag. Keu & \\
\hline $\begin{array}{l}\text { Priority }=2 \\
\text { Upload }\end{array}$ & $\begin{array}{l}\text { Download } \\
\text { Max-limit }=5 \text { Mbps }\end{array}$ & \\
\hline $\begin{array}{l}\text { Upload } \\
\text { Max-limit }=5 \text { Mbps }\end{array}$ & Limit $-\mathrm{At}=\mathbf{4} \mathrm{Mbps}$ & \\
\hline $\begin{array}{l}\text { Max-limit }=5 \mathrm{Mbps} \\
\text { Limit-At }=2 \mathrm{Mbps}\end{array}$ & Priority $=2$ & \\
\hline $\begin{array}{l}\text { Limit-At = } 2 \text { Mbps } \\
\text { Priority }=2\end{array}$ & Upload & \\
\hline${ }^{*}$ Q5 5 dan Q6 -Bag. Umum & Limit - At $=4 \mathrm{Mbps}$ & \\
\hline Download & Priority $=2$ & \\
\hline Max-limit $=4$ Mbps & & \\
\hline Limit-At $=\mathbf{3} \mathrm{Mbps}$ & ${ }^{*} \mathrm{Q} 23$ dan Q24 R.R & \\
\hline Priority $=3$ & Sandat & \\
\hline Upload & Download & \\
\hline Max-limit $=4$ Mbps & Max-limit $=6$ Mbps & \\
\hline Limit-At $=\mathbf{3} \mathrm{Mbps}$ & Limit $-A t=5 \mathrm{Mbps}$ & \\
\hline Priority $=3$ & Priority = 1 & \\
\hline *Q7-Q12 : Bag. Kepeg, Yankes, & Max-limit $=6 \mathrm{Mbps}$ & \\
\hline SDK, R.R Cempaka, R.R Sandat, & Limit-At $=5 \mathrm{Mbps}$ & \\
\hline P2-Kesmas & Priority $=1$ & \\
\hline Download Max-limit = 3 & ${ }^{*}$ Q25 dan Q26 & \\
\hline $\begin{array}{l}\text { Mbps, Limit-At = } 2 \text { Mbps, } \\
\text { Priority = 3) }\end{array}$ & Bidang Kesmas & \\
\hline & Download & \\
\hline *Q13 - Q18 : Bag. Kepeg, & Max-limit $=4$ Mbps & \\
\hline Yankes, SDK, R.R Cempaka, & Limit - At $=\mathbf{3} \mathrm{Mbps}$ & \\
\hline R.R Sandat, P2-Kesmas & Priority = 3 & \\
\hline Upload & Upload & \\
\hline Max-limit $=3 \mathrm{Mbps}$ & Max-limit $=4$ Mbps & \\
\hline Limit $-\mathbf{A t}=2 \mathrm{Mbps}$ & Limit - At $=\mathbf{3}$ Mbps & \\
\hline Priority $=3$ & Priority $=\mathbf{3}$ & \\
\hline
\end{tabular}

Gambar 4: Struktur Hierarchical Token Bucket Dengan Kondisi Menerima Paket Melalui Radio WE

I Gede Abi Yodita Utama: Manajemen Jaringan Internet di... 


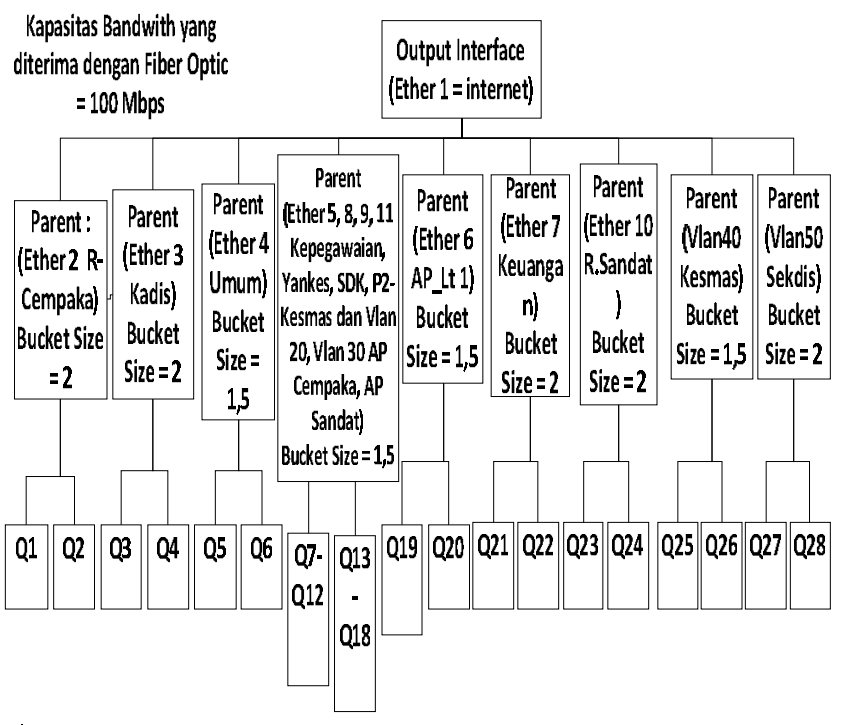

*Q1 dan Q2 Cempaka Tele

Download

Max-limit $=20$ Mbps
Limit - At $=18$ Mbps

Priority $=1$

Upload

Max-imit $=20 \mathrm{Mbps}$

Limit - At $=18 \mathrm{Mbps}$

Priority $=1$

${ }^{*}$ Q dan Q4-Kadis

Download

Max-limit $=15$ Mbps

Limit - At $=13$ Mbps

Priority $=2$

Upload

Max-limit $=15$ Mbps

Limit - At $=13$ Mbps

Priority $=2$

*Q5 dan Q6 -Bag. Umum

Download

Max-imit $=10$ Mbps

Limit - At $=8$ Mbps

Priority $=3$

Upload

Max-limit $=10$ Mbps

Limit - At $=8 \mathrm{Mbps}$

Priority $=3$

*Q7-Q12 : Bag, Kepeg, Yankes,

SDK, R.R Cempaka, R.R Sandat,

P2-Kesmas

Download Max-limit $=10$

Mbps, Limit $-A t=8 \mathrm{Mbps}$

Priority=3)

*Q13-Q18: Bag, Kepeg,

Yankes, SDK, R.R Cempaka,

R.R Sandat, P2-Kesmas

Upload

Max-limit $=10$ Mbps

Limit - At $=8 \mathrm{Mbps}$

Priority $=3$

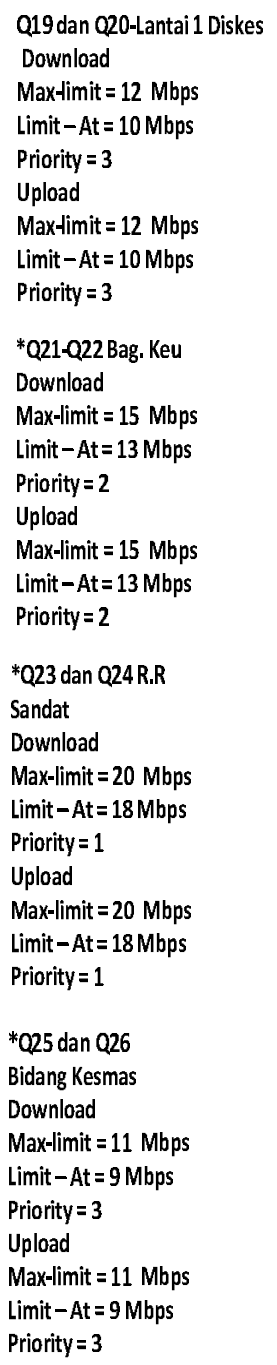

*Q27dan Q28

Sekretaris

Download

Max-limit = 12

Mbps

Limit - At $=10$

Mbps

Priority $=2$

Upload

Max-limit = 12

Mbps

Limit - At $=10$

Mbps

Priority $=2$

Gambar 5: Struktur Hierarchical Token Bucket Dengan Kondisi Menerima Paket Melalui Fiber Optic

\section{IV.HASIL DAN PEMBAHASAN}

\section{A. Mangle}

Langkah pertama yang dilakukan pada saat melakukan implementasi HTB dengan MikroTik OS adalah dengan menyusun mangle, mangle ini berfungsi sebagai identitas suatu paket dari traffic data pada saat melewati router yang digunakan pada saat melakukan manajemen bandwith internet. Setiap paket yang diterima akan ditandai terlebih dahulu agar koneksi yang dialirkan pada saat melakukan proses manajemen sesuai dengan paket yang ditentukan. Gambar 6 meupakan tampilan dari mangle dengan aplikasi winbox.

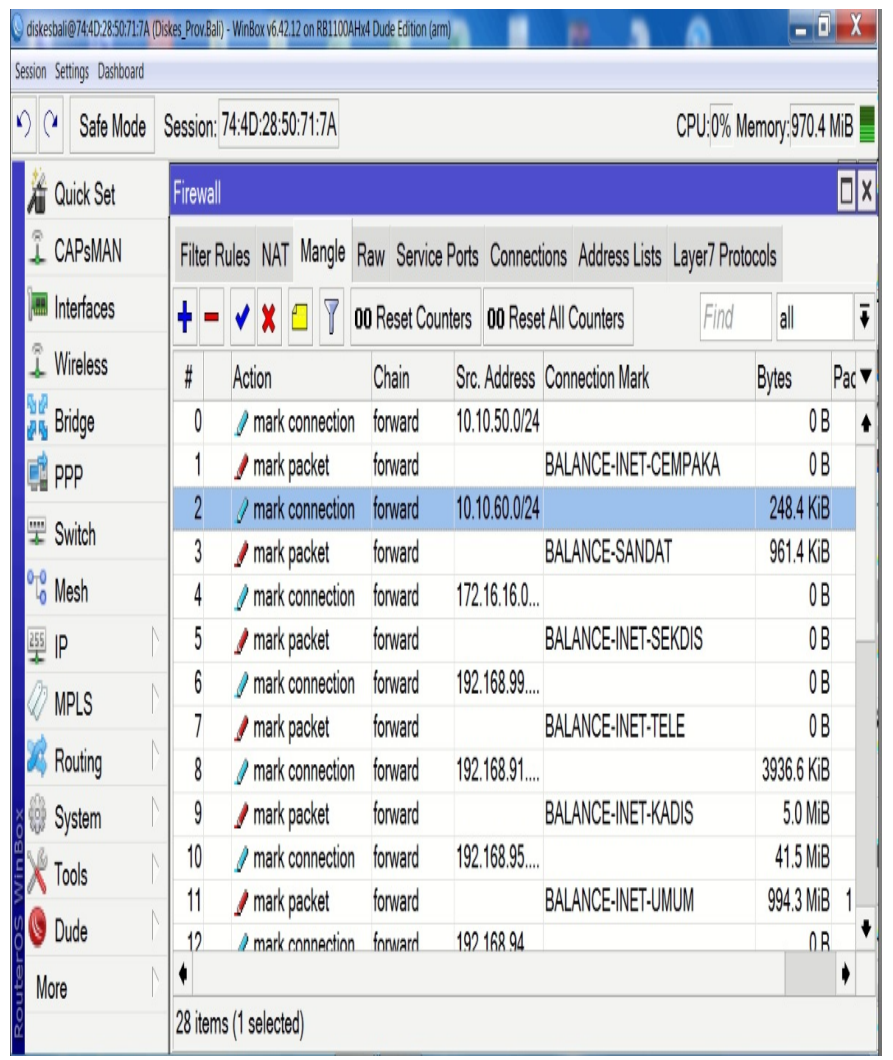

Gambar 6: Penyusunan Mangle pada MikroTik melalui apilkasi windows Winbox

Dalam mangle juga dapat dilakukan pemantauan traffic terkait besaran paket yang diterima oleh client berdasarkan jenis paket yang ditentukan. Gambar 7 adalah traffic dari pemantauan besaran paket yang diterima pada salah satu jenis paket dalam kondisi sibuk. 


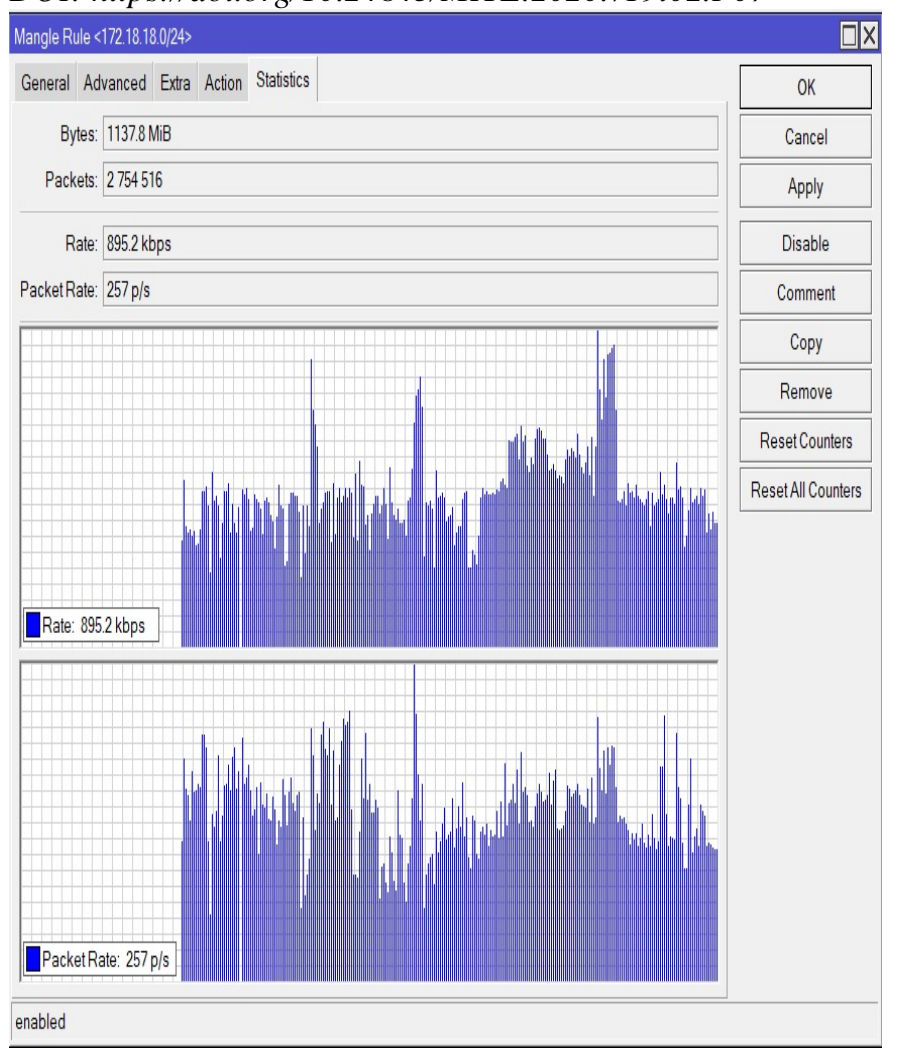

Gambar 7:Pemantauan Traffic Salah Satu Jenis Paket Pada Mangle

\section{B. Hasil HTB}

Setelah menentukan identitas paket dengan mangle langkah selanjutnya adalah membuat queue dengan tujuan untuk melakukan pembagian bandwith berdasarkan kebutuhan pada masing-masing bagian ataupun kebutuhan lain seperti pertemuan virtual melalui teleconference. Selama masa pandemi Covid-19 kebutuhan akan pertemuan secara virtual meningkat di lingkungan Pemerintah Provinsi Bali.

Dalam penelitian ini akan dirancang implementasi HTB melalui queue dalam kondisi menerima paket melalui Radio WE, sedangkan untuk implementasi HTB dengan kondisi menerima paket melalui fiber optic tidak dapat dilakukan karena pada saat melakukan observasi di lapangan terjadi masalah pada fiber optic. Untuk rancangan skema HTB dalam kondisi menerima paket melalui fiber optic dapat dilihat pada Gambar 5.

Dalam quеие telah ditetapkan identitas paket pada masingmasing bagian, jumlah besaran bandwith yang telah disesuaikan berdasarkan kebutuhan pada masing-masing bagian. Untuk penjadwalan paket melalui queue baik untuk pembagian download dan upload di Dinas Kesehatan Provinsi Bali dapat dilihat pada Gambar 8 dan Gambar 9.

\section{Queve List}

Simple Quveres Interfoce Quveres Queve Tree Queve Types

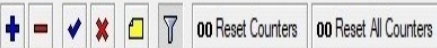

Name $\quad \bar{\dagger}$ contains $\quad \bar{\dagger}$ downlosd

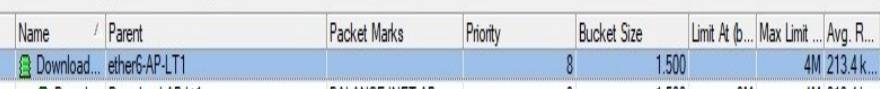

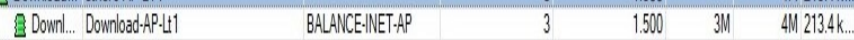

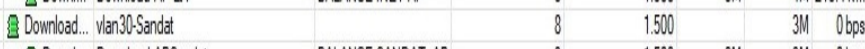

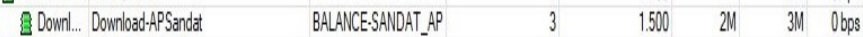

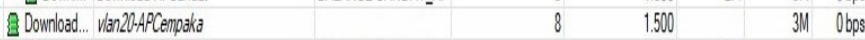

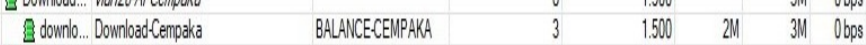

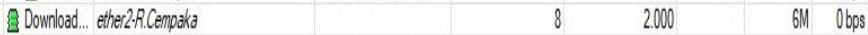

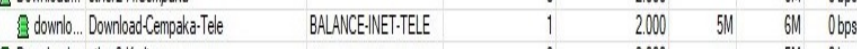

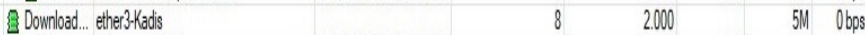

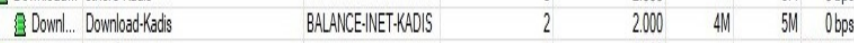

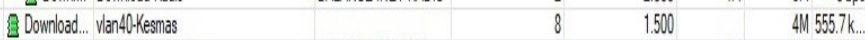

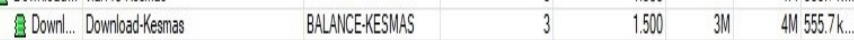

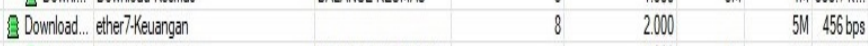

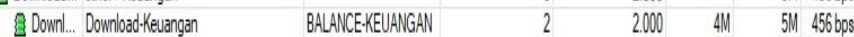

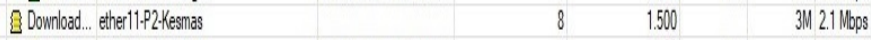

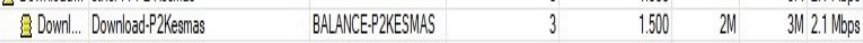

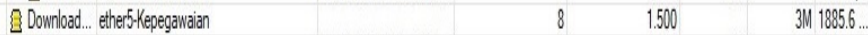

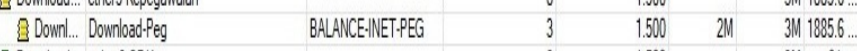

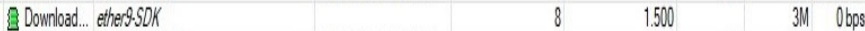

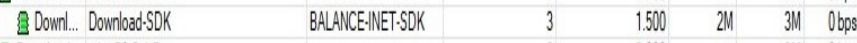

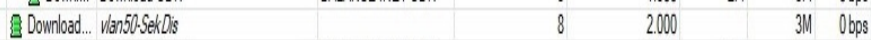

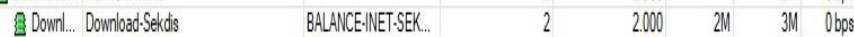

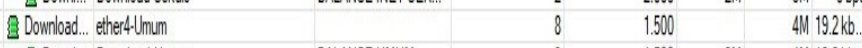

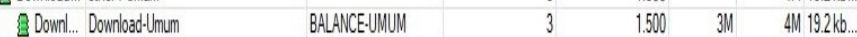

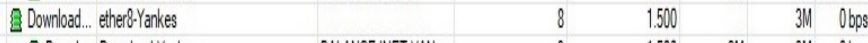

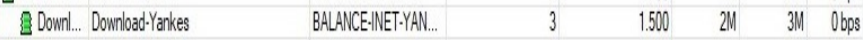

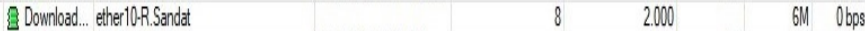

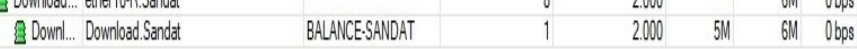

Gambar 8 :Queue Pembagian Untuk Download

Implementasi HTB dalam queue dimulai dengan pengaturan bucket size yang digunakan untuk memeriksa kondisi suatu token agar masing-masing bidang dapat menerima besaran paket melebihi dari kapasitas paket yang dikirimkan yang disesuaikan dengan prioritas pemberian token. Jika token sesuai dengan kapasitas dari bucket size maka token akan dibuang dan paket dapat melewati antrian. Jika token tidak tersedia sesuai dengan kapasitas bucket maka paket tetap pada awal antrian dan menunggu hingga jumlah token yang sesuai tersedia. Penetapan ukuran bucket size pada masingmasing bidang disesuaikan dengan prioritasnya jika termasuk prioritas 1 dan 2 maka ditetapkan ukuran bucket sebesar 2,0, apabila termasuk prioritas 3 maka ukuran bucket sebesar 1.5. Untuk pengaturan token dalam queue ditentukan melalui CIR (limit-At) dan MIR (Max-Limit). Hasil token bucket dalam queue pada saat proses download dan upload dapat dilihat pada Gambar 10 dan Gambar 11 


\begin{tabular}{|c|c|c|c|c|c|c|c|c|}
\hline \multicolumn{9}{|c|}{ Simple Queves Interface Queves Queve Tree Queve Types } \\
\hline \multicolumn{9}{|c|}{$\downarrow=\checkmark \times \square \nabla \quad 00$ Reset Counters 00 Reset Al Counters } \\
\hline \multicolumn{9}{|c|}{ † upload } \\
\hline Name & Parent & & Packet Makiss & Prioith & & & $\operatorname{Limin} A A_{b}^{b} \ldots$ & Max Limit ... Avg. R... \\
\hline SO Upload-A.... & ether1-Intemet & & & & 8 & 1.500 & & 4M $203.2 \mathrm{k} \ldots$ \\
\hline S Upload... & Upload-AP-L1 & & BALANCE-NET-AP & & 3 & 1.500 & 3M & 4M $203.2 \mathrm{k} .$. \\
\hline § Upload.A... & ether 1 -htemet & & & & 8 & 1.500 & & 3M Obps \\
\hline S Upload... & Upload-APSandat & & BALANCE-SANDAT_AP & & 3 & 1.500 & $2 M$ & 3M Obps \\
\hline SO Upload.Ce... & ether 1 -htemet & & & & 8 & 1.500 & & 3M Obps \\
\hline S Upload... & Upload-Cempaka & & BALANCE-INET & & 3 & 1.500 & $2 M$ & 3M Obps \\
\hline S) Upload.Ce... & ether 1 -Intemet & & & & 8 & 2.000 & & 6M Obps \\
\hline S Upload... & Upload-Cempaka-Tete & & BALANCE-INETTTELE & & 1 & 2.000 & $5 \mathrm{M}$ & 6M Obps \\
\hline (2) Upload-Ka... & ether1-Intemet & & & & 8 & 2.000 & & 6M Obps \\
\hline E Upload... & Upload-Kadis & & BALANCE-INETTKADIS & & 2 & 2.000 & $5 M$ & 6M Obps \\
\hline SO Upload.Ke... & ether 1 -ntemet & & & & 8 & 1.500 & & 4M 401.9k... \\
\hline S Upload... & Upload-Kesmas & & BALANCE-KESMAS & & 3 & 1.500 & 3M & 4M $401.9 \mathrm{k} \ldots$ \\
\hline 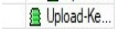 & ether 1 -Intemet & & & & 8 & 2.000 & & 5M $3.2 \mathrm{kbps}$ \\
\hline S Upload... & Upload-Keuangan & & BALANCE-KEUANGAN & & 2 & 2.000 & 4M & 5M $3.2 \mathrm{kbps}$ \\
\hline 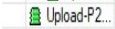 & ether1-Intemet & & & & 8 & 1.500 & & 3M $139.1 \mathrm{k} \ldots$ \\
\hline S Upload... & Upload.P2Kesmas & & BALANCE.P2KESMAS & & 3 & 1.500 & $2 M$ & 3M $139.1 \mathrm{k} . .$. \\
\hline (1) Upload.Peg & ether 1 -Intemet & & & & 8 & 1.500 & & 3M 1336 bps \\
\hline S Upload... & Upload-Peg & & BALANCE-INET.PEG & & 3 & 1.500 & $2 M$ & 3M 1336 bps \\
\hline SUpload-SDK & Kether:S.5DK & & & & 8 & 1.500 & & 3M Obps \\
\hline O Upload... & Upload-SDK & & BALANCE-INET.SDK & & 3 & 1.500 & $2 \mathrm{M}$ & 3M Obps \\
\hline SO Upload-Sa... & ether 1 -Intemet & & & & 8 & 2.000 & & 6M Obps \\
\hline S Upload... & Upload-Sandat & & BALANCE-SANDAT & & 1 & 2.000 & $5 \mathrm{M}$ & 6M Obps \\
\hline A Upload-Se... & ether1-Intemet & & & & 8 & 2.000 & & 3M Obps \\
\hline S Upload... & Upload-Sekdis & & BALANCE-INET.SEK... & & 2 & 2.000 & $2 M$ & 3M Obps \\
\hline (2) Upload-U.... & ether 1-Intemet & & & & 8 & 1.500 & & 3M $86.4 \mathrm{~kb} .$. \\
\hline S Upload... & Upload-Umum & & BALANCE-UMUM & & 3 & 1.500 & $2 M$ & $3 \mathrm{M} 86.4 \mathrm{~kb} . \ldots$ \\
\hline SO Upload-Ya.... & ether 1 -Intemet & & & & 8 & 1.500 & & 3M $168 \mathrm{bps}$ \\
\hline S Upload... & Upload-Yankes & & BALANCE-INETYYAN... & & 3 & 1.500 & $2 M$ & 3M $168 \mathrm{bps}$ \\
\hline
\end{tabular}

28 items out of 56 (1 selected) $\quad$ OB queved $\quad$ Opackets queved

Gambar 9 : Queue Pembagian Untuk Upload

\begin{tabular}{|l|l|l|l|l|l|l|}
\hline Queve List \\
\hline Simple Queves interface Queves Queve Tree \\
\hline
\end{tabular}

Gambar 10 :Hasil HTB pada saat manajemen bandwith untuk proses download

Dalam Gambar 10 dapat dilihat manajemen bandwith dengan HTB pada masing-masing bagian di Dinas Kesehatan telah disusun berdasarkan hirarki. Hirarki ditentukan dengan parent pada masing-masing queue tiap-tiap bagian. Hasil pemantauan menunjukkan bahwa bandwith yang diterima pada saat proses download tidak melebihi Maximum Information Rate (MIR) dengan kelebihan bandwith yang telah ditentukan berdasarkan bucket size pada masing-masing bagian/bidang. Pada bagian/bidang yang melebihi kapasitas dari MIR (Max-Limit), maka akan dilakukan pengurangan bandwith sampai batas CIR (Limit-At), pengurangan tersebut ditentukan dari jumlah token dalam bucket size, semakin banyak penggunaan token maka semakin cepat bandwith tersebut dikurangi hingga batas CIR pada saat kondisi sibuk. Pendisitribusian bandwith juga disesuaikan dengan priority pada queue tersebut.

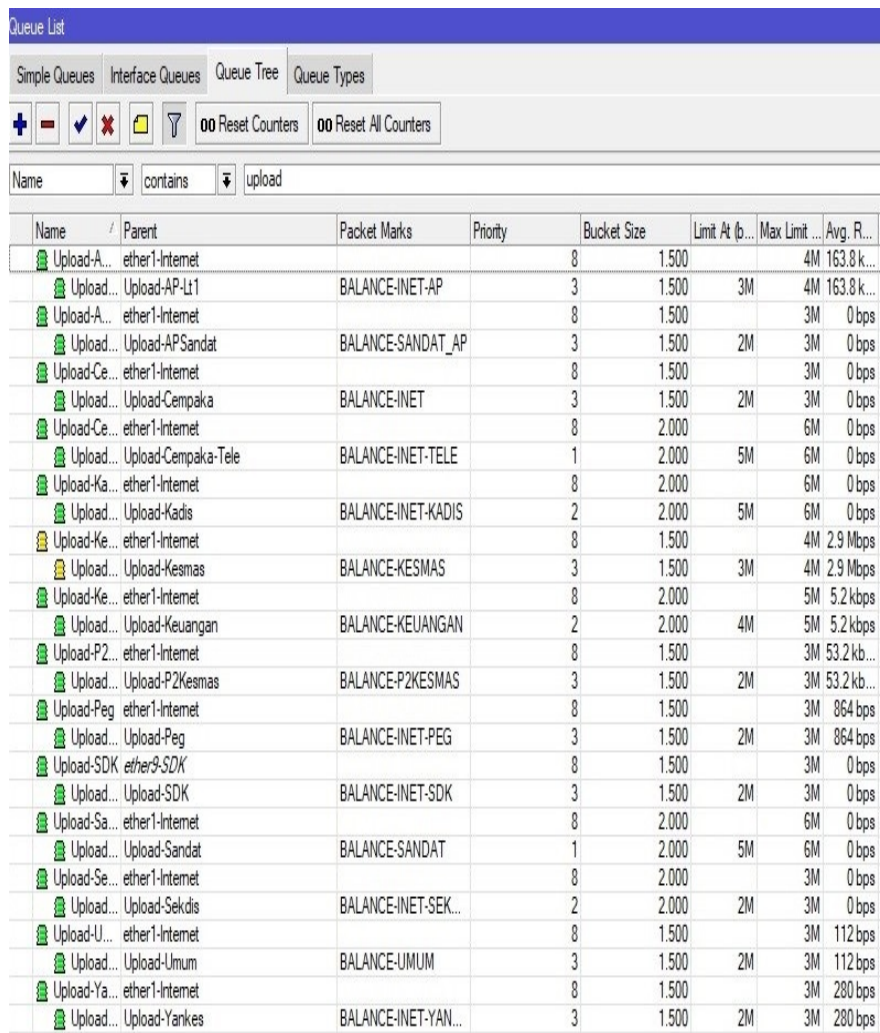

28 items out of 56 ( 1 selected $) \quad$ OB queved $\quad$ Opackets queved

Gambar 11 :Hasil HTB pada saat manajemen bandwith untuk proses upload

Gambar 11 adalah hasil pemantauan bandwith pada saat proses upload dimana proses pengurangan bandwith sama dengan proses download pada saat kondisi traffic sedang sibuk. Pengurangan dilakukan tidak sampai kurang dari batas Committed Information Rate (CIR) pada saat kondisi sibuk.

\section{Kesimpulan}

Implementasi HTB dengan menggunakan MikroTik dapat diterapkan dalam queue, dimana melibatkan parent untuk menyusun hirarki, priority untuk menentukan prioritas 
Majalah Ilmiah Teknologi Elektro, Vol. 19, No. 2, Juli - Desember 2020

DOI: https://doi.org/10.24843/MITE.2020.v19i02.P07

pendistribusian bandwith, CIR (limit-At) dan MIR (Max-Limit) diumpamakan sebagai token rate dan Bucket size yang diumpamakan sebagai Bucket.

Implementasi HTB pada manajemen jaringan internet di Dinas Kesehatan Provinsi Bali terbukti dapat menghasilkan pembagian bandwith secara merata yang ditentukan berdasarkan bucket size, priority, nilai CIR dan MIR. Pembagian tersebut juga tidak mengganggu akses dan konektivitas antara satu bagian/bidang dengan yang lainnya. Selain itu, juga dapat dilakukan pemantauan traffic bandwith pada tiap-tiap bagian.

Untuk pengembangan manajemen jaringan internet di Dinas Kesehatan Provinsi Bali dapat menerapkan metode penjadwalan lainnya seperti FIFO (First in First Out), SFQ (Stochastic Fairness Queuing), Burst dan CBQ (Class Base Queueing).

\section{REFERENSI}

[1] Eka Putra, I. G. P Mastawan, Giriantari, I. A, Lie Jasa, "Monitoring Penggunaan Daya listrik Sebagai Implementasi Internet of Things Berbasis Wireless Sensor Network," Majalah Ilmiah Teknologi Elektro, [S.1.], v. 16, n. 3, p. 50 - 55, dec. 2017, 2017.

[2] S. I. M. Rai, Linawati, Sastra N. Putra, "Analisis Pemanfaatan Internet di Pusat Pemerintahan Kabupaten Badung,” Majalah Ilmiah Teknologi Elektro, [S.1.], v. 17, n. 2, p. 185-190, nov. 2018, 2018.

[3] A.A Sri, "Impact of Industrial Revolution 4.0 and the Utilization of Digital Media Technology towards Siber Community Behavior," in Proc. Community Development, 2018, p. 483-494.

[4] P. Yukos, E. Usman, S. Suroyo, "Optimization of Wireless Network Performance Using the Hierarchical Token Bucket," Journal of Information Systems and Informatics, Vol. 1, No. 1, March 2019, 2019.

[5] A. Yunus. "Implementasi Quality Of Service Dengan Metode HTB (Hierarchical Token Bucket) pada PT.Komunika Lima Duabelas," JELIKU - Jurnal Elektronik Ilmu Komputer Udayana, [S.1.], p. 1-7, mar. 2013, 2013.

[6] M. P Guntur. "Concept of Analysis and Implementation of Burst On Mikrotik Router," IOP Conf. Series: Journal of Physics: Conf. Series 1114, 2018.

[7] S. Ren, W. Dou and Y. Wang, "A deterministic network calculus enabled QoS routing on software defined network," 2017 IEEE 9th International Conference on Communication Software and Networks (ICCSN), Guangzhou, pp. 182-186, 2017.

[8] J. Wang and P. Shi, "Research on Bandwidth Control Technology Based on SDN," 2018 2nd IEEE Advanced Information Management,Communicates,Electronic and Automation Control Conference (IMCEC), Xi'an, pp. 705-708, 2018.

[9] D. Lesmana Siahaan, Muhammad \& Panjaitan, Melva \& Siahaan, Andysah Putera Utama, "MikroTik Bandwidth Management to Gain the Users Prosperity Prevalent," International Journal of Emerging Trends \& Technology in Computer Science, 42.,218-222, 2016.

[10] Bernadu I. N, N. Gunantara, K. Oka Saputra, "Analisis Kinerja Jaringan Internet dengan Metode Class Based Queueing di Universitas Dhyana Pura," Majalah Ilmiah Teknologi Elektro, [S.1.], v. 18, n. 1, p. 133-140, may 2019, 2019

[11] SIA Mikrotīkls, Latvia, 2002, “About Us on Mikrotik" [Online]. Available: https://mikrotik.com/aboutus [Accessed: 26-May-2020].

I Gede Abi Yodita Utama: Manajemen Jaringan Internet di... 
[Halaman ini sengaja di kosongkan] 